\title{
Gás em folhelho no Brasil: os impactos da Moratória Ambiental
}

Cardoso, G.L.*, FAGEOF - UFPa; Furtado, G. R., FAGEO - UFPa; Luczynski, E., IG - UFPa

Copyright 2018, SBGf - Sociedade Brasileira de Geofísica

Este texto foi preparado para a apresentação no VIII Simpósio Brasileiro de Geofísica, Salinópolis, 18 a 20 de setembro de 2018. Seu conteúdo foi revisado pelo Comitê Técnico do VIII SimBGf, mas não necessariamente representa a opinião da SBGf ou de seus associados. É proibida a reprodução total ou parcial deste material para propósitos comerciais sem prévia autorização da SBGf.

\section{Resumo}

Nowadays, shale gas is one more option to world energy matrix due its high heat capacity e low emissions. However, there is many criticisms about its controversy exploration, the fracking. Some countries have economic and legal barriers against shale gas exploration.

In Brazil, fracking is under an environmental moratorium, it aims an evaluation of environmental impacts of fracking before the exploration. In this paper, there is a discussion by a SWOT analysis of moratorium by positive aspects and negative points.

\section{Introdução}

A diversificação da matriz energética mundial implica na necessidade de implementação de diferentes técnicas de exploração de hidrocarbonetos, que por vezes não eram considerados por serem inviáveis economicamente ou por possuírem características não convencionais quanto as técnicas de extração (EPE, 2014). Em contrapartida, a necessidade do emprego de energias mais limpas e eficazes desponta como grande vantagem para os recursos não convencionais, sobretudo o gás em folhelho (shale gas).

Utilizado em países como EUA e Argentina (ANP, 2012), os quais apresentam pioneirismo nas frentes de produção e de técnicas para manejo de exploração e atenuação de impactos ambientais, este recurso apresenta dificuldades de implantação no modelo de produção no Brasil devido ao seu principal método de exploração: o fraturamento hidráulico (Basto, 2014), cujos impactos ainda não foram devidamente segmentados e analisados nas formações brasileiras.

Para o aproveitamento principal dessa técnica, faz-se necessário o uso e desenvolvimento de métodos especiais de exploração, destacando-se a perfuração direcional associada ao fraturamento (Basto, 2014), com a injeção de água, areia e produtos químicos para aumentar a permeabilidade da rocha (Martins \& Fuser, 2016). Devido aos diferentes tipos de comportamentos mecânicos da rocha e por ser uma técnica altamente incisiva, existem possibilidades reais de danos e desequilíbrios ambientais como contaminações de lençóis freáticos e indução de sismicidades locais (IBase, 2015).

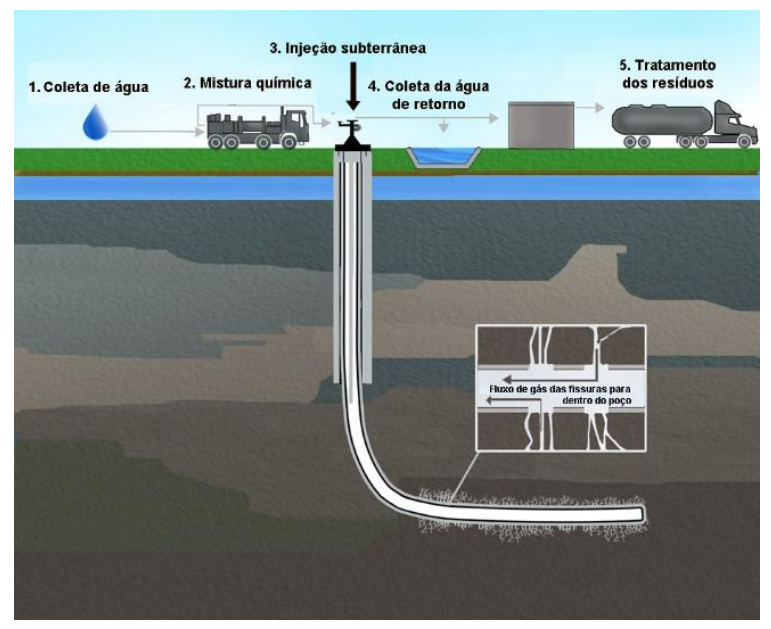

Figura 1 - Esquematização dos processos envolvidos na execução do fraturamento hidráulico. (Fonte: iBase, 2015).

Os riscos decorrentes da sua aplicação levaram a suspenção em alguns países e reformulação da legislação vigente, para se adequar à esta tecnologia em desenvolvimento. No Brasil, isto ocorreu com o estabelecimento da Moratória Ambiental sobre a exploração de gás em folhelho, impedindo a exploração deste recurso em qualquer bacia do país (BRASIL, 2013).

\section{Metodologia}

Realizou-se uma pesquisa bibliográfica acerca dos conceitos fundamentais relacionados ao gás natural e sua interação com reservatórios não convencionais, sobretudo os compostos por folhelhos de baixa permeabilidade (Jacomo, 2014), objetivando o desenvolvimento de conhecimento sobre os processos de geração e adsorção do gás em folhelho (Monteiro, 2013), bem como sua ocorrência primordial em bacias paleozóicas (Basto, 2014). Em seguida, analisou-se o panorama internacional da exploração do gás em folhelho e sua inserção na economia mundial, para posterior apresentação no contexto exploratório brasileiro. 
Uma revisão bibliográfica propiciou o arcabouço teórico referente ao método do fraturamento hidráulico, seu aprimoramento e processos envolvidos em sua aplicação, além da correlação com a perfuração direcional (Basto, 2014) e a Geofísica, sobretudo no estudo de atributos sísmicos para o mapeamento e monitoramento de fraturas (Harilal \& Tandon, 2012). Após o entendimento da Moratória Ambiental (BRASIL, 2013), seus impactos positivos e negativos sobre a exploração de gás em folhelho no Brasil foram discretizados em uma análise SOWT, a qual consiste em uma ferramenta administrativa para elaboração de estratégias, partindo da identificação de pontos fortes e fracos, desvantagens e oportunidades, em ambientes econômicos e empresariais (Neto, 2011).

\section{Discussão e Resultados}

Em junho de 2013, a Agência Nacional de Petróleo, Gás Natural e Biocombustíveis (ANP) publicou o edital de chamada para a $12^{\mathrm{a}}$ Rodada de Licitações de Blocos de Exploração, ocorrida em 28 de novembro do mesmo ano (Sanberg et. al., 2015). Contudo, a disponibilidade, neste edital, de 11 blocos potenciais para gás em folhelho provocou preocupação em órgãos jurídicos, comunidade científica nacional e sociedade civil devido a possibilidade do uso do fraturamento hidráulico.

Os 11 blocos integrantes estão localizados nas bacias do Acre, Solimões, Parnaíba, Recôncavo e do Paraná (iBase, 2015; PDE, 2014). Dentre estas bacias, a Bacia do Paraná destaca-se tanto devido ao seu potencial para a acumulação de gás não convencional - segundo estimativas, concentra cerca de $50 \%$ deste recurso no país (Scheibe et al., 2013) - quanto pela sua importância ambiental para a Região Sul e Sudeste do Brasil, pois comporta o Sistema Aquífero Guarani (SAG) e Sistema Aquífero Serra Geral (SASG) entrelaçados na extensão da bacia. Os folhelhos geradores de gás da Formação Irati estão estratigraficamente abaixo das Formações Botucatu e Pirambóia (formadoras do SAG) e das rochas vulcânicas da Formação Serra Geral (SASG) (Scheibe et al., 2013); vale ressaltar que estes recursos hídricos em subsuperfície são de alta importância para a região, já que a hidrografia superficial segue abalada pela intensa poluição a qual é submetida.

Em resposta a disponibilização destes blocos pela ANP sem estudos prévios de impactos ambientais, foram organizadas manifestações em cidades do Paraná e do Piauí, as quais seriam afetadas diretamente pela exploração via faturamento hidráulico, além da proibição da concessão de alvará pelas prefeituras para utilização do faturamento em cidades do Paraná, como Toledo e Cascavel (iBase, 2015)

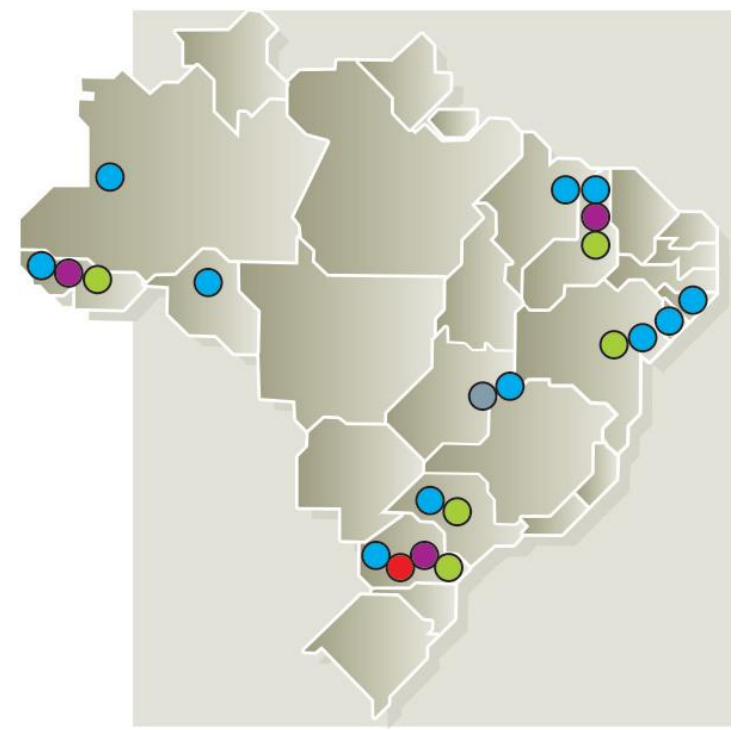

Figura 2 - O mapa da exploração por fraturamento hidráulico no Brasil: em azul, os blocos não convencionais leiloados durante a $12^{\underline{a}}$ Rodada de Licitações da ANP, em 2013; em verde, cidades nas quais o Ministério Público entrou com ações civís públicas para o impedimento da utilização do fraturamento; em roxo, locais com manifestações populares; em vermelho, cidades cujas prefeituras proibiram o emprego do fraturamento; em cinza, o desenvolvimento da moratória ambiental. (Fonte: iBase, 2015).

Diante destes acontecimentos, o Congresso Nacional elaborou o Projeto de Lei № 6.904 de 2013, denominado de "Moratória Ambiental", liderado pelo deputado federal Sarney Filho, com o objetivo de impedir a exploração de recursos não convencionais via fraturamento hidráulico no Brasil por um período de 5 anos, partindo da data de sua publicação no Diário Oficial da Uníão. Este PL fez uso do Princípio da Precaução, definido no Princípio 15 da Declaração da Conferência Rio/92 sobre Meio Ambiente e Desenvolvimento Sustentável (Sanberg et. al., 2015) e se baseou no Artigo 225 da Constituição Federal Brasileira, o qual trata sobre a exploração do meio ambiente e sua interferência no equilíbrio do mesmo.

A moratória ambiental foi elaborada para a promoção de um tempo para reflexão (BRASIL..., 2013), objetivando a realização de estudos sobre a viabilidade da exploração de recursos não convencionais no país, seus benefícios econômicos e energéticos (visto que sua demanda pode ser suprida por alternativas menos problemáticas), ambos pautados na análise de impactos ambientais e sociais advindos da utilização do fraturamento hidrálico nas áreas sob regime de concessão, bem como o desenvolvimento de mecanismos de mitigação destes impactos. Além disto, a Moratória propiciou a elaboração de leis as quais regulamentem a exploração de gás não convencional em áreas ambientais, a exemplo da Resolução da ANP № 21 , de 10 de abril de 2014, a qual estabelece os requisitos 
essenciais de segurança operacional e de preservação do meio ambiente para a atividade de fraturamento hidráulico em reservatórios não convencionais (BRASIL..., 2014). Ademais, promoveu debate adequado sobre o assunto, fazendo com que as informações corretas sobre a exploração do gás em folhelho saiam do âmbito acadêmico e atinjam a população, por meio de propagandas, palestras e métodos semelhante.

Entretanto, a Moratória influenciou no afastamento de empresas ligadas ao setor petrolífero e de gás natural, devido a rigidez da legislação, com consequente perda de investimentos e de entrada de capital no país, além do atraso na geração de empregos, visto que a exploração do gás em folhelho empregaria mão de obra de diferentes qualificações. Estimulou o retrocesso do país quanto a inserção de novas fontes de energia na matriz energética nacional e do desenvolvimento de tecnologia própria para a extração, beneficiamento e distribuição da mesma, ficando atrás de países como a Argentina (gás em folhelho) e a China (hidratos de metano). Em somatório, promoveu a manutenção dos altos preços de gás no país, tendo em vista que a nova fonte de energia injetaria grande quantidade do produto na indústria petrolífera (levando em consideração a boa ocorrência do recurso nas bacias sedimentares do país), aumentando a sua oferta e reduzindo os preços.

\section{Conclusões}

Os resultados obtidos indicam a validade do estabelecimento da moratória há cinco anos, pois o Brasil ainda não estava técnica e juridicamente preparado para a exploração de recursos não convencionais nas bacias nacionais, haja vista a ausência de estudos de impactos ambientais na época e a falta de dimensão teórica de possíveis danos derivados do processo de fraturamento hidráulico.

\section{Agradecimentos}

Agradecimentos ao Prof. Dr. Estanislau Luczynski, pela excelente orientação e paciência no decorrer do desenvolvimento das pesquisas.

Tabela 1 - Análise SWOT acerca dos impactos derivados da aplicação da Moratória Ambiental sobre a exploração de gás em folhelho por fraturamento hidráulico no país.

\begin{tabular}{|c|c|}
\hline $\begin{array}{c}\text { Forças } \\
\text { Discussão de questões ambientais } \\
\text { Apoiada por órgãos de defesa do meio ambiente } \\
\text { e pelas pessoas que seriam afetadas pela } \\
\text { exploração } \\
\text { Legislação precursora no país }\end{array}$ & $\begin{array}{l}\text { Fraquezas } \\
\text { Baixo apoio por boa parte do Congresso Nacional } \\
\text { Proibição da realização de qualquer teste in situ } \\
\text { com o fraturamento hidráulico } \\
\text { Deixa lacunas sobre alguns aspectos da } \\
\text { exploração não convencional no Brasil }\end{array}$ \\
\hline Oportunidades & Ameaças \\
\hline $\begin{array}{l}\text { Realização de estudos sobre o real potencial } \\
\text { econômico do gás em folhelho no Brasil }\end{array}$ & $\begin{array}{c}\text { Afastamento de empresas ligadas ao setor de gás } \\
\text { natural devido a rigidez da legislação }\end{array}$ \\
\hline $\begin{array}{l}\text { Realização de estudos para a detecção dos } \\
\text { impactos ambientais da exploração }\end{array}$ & $\begin{array}{l}\text { Perda de investimentos e de geração de } \\
\text { empregos }\end{array}$ \\
\hline $\begin{array}{l}\text { Desenvolvimento de métodos para a mitigação } \\
\text { dos impactos }\end{array}$ & $\begin{array}{l}\text { Manutenção dos altos preços de gás no país } \\
\text { devido a não inserção de novas jazidas }\end{array}$ \\
\hline
\end{tabular}




\section{Referências}

AGÊNCIA Nacional do Petróleo, Gás Natural e Biocombustíveis. Boletim Anual de Preços 2012: preços do petróleo, gás natural e combustíveis nos mercados nacional e internacional. Rio de Janeiro, 2012. Disponível em: <http://www.anp.gov.br/?dw=59757> . Acesso em: 18 dez. 2013.

BASTO, Jorge Manuel Portas. Problemática do Shale Gas: da Estimação de Reservas aos métodos de Desenvolvimento e Produção. 2014.

BRASIL. Projeto de Lei no 6.904-A, de 6 de dezembro de 2013. Estabelece medidas relativas à atividade de exploração de gás de folhelho (também conhecido como gás de xisto). Brasília, DF, 6 dez. 2013. Disponível em: $<$ http://www.camara.gov.br/sileg/integras/1365569.pdf > Acesso em: 18 dez. 2017.

BRASIL. Resolução ANP nำ 21, de 10 de abril de 2014. Estabelece os requisitos essenciais e os padrões de segurança operacional e de preservação do meio ambiente para a atividade de Fraturamento Hidráulico em Reservatório Não Convencional. Diário Oficial da União, Brasília, DF, 11 abr. 2014. Disponível em:

$<$ http://www.documentador.pr.gov.br/documentador/pub.d o\%3Faction\%3Dd\%26uuid\%3D\%40gtf-escribaminerop\%40cf54392f-95ed-4458-9ed9$\underline{05 d 800543 b 4 e+\& c d=1 \& h l=p t-B R \& c t=c l n k \& g l=b r}>$ Acesso em 18 dez. 2017.

DE PESQUISA ENERGÉTICA, Empresa. Plano Decenal de Energia. 2014.

Harilal; Tandon, A.K. 2012. Unconventional Shale-gas plays and their characterization through 3-D seismic attributes and logs. $9^{\text {th }}$ Biennial International Conference \& Exposition on Petroleum Geophysics. P-083. p. 1-8.

INSTITUTO Brasileiro de Análises Sociais e Econômicas, iBase. Fracking no Brasil: Riscos e ameaças da exploração do "gás de xisto". Observatório da Indústria Extrativa, no 1, dez. 2015. Disponível em:

$<$ http://industriaextrativa.ibase.br/files/2016/04/Fracking I base n01 dez2015.pdf > Acesso em: 18 dez. 2017.

JACOMO, Julio Cesar Pinguelli. Os hidrocarbonetos não convencionais: uma análise da exploração do gás de folhelho na Argentina à luz da experiência norteamericana. 2014. Tese de Doutorado. Universidade Federal do Rio de Janeiro.

MARTINS, Rhodiney Vaz; FUSER, Igor. PANORAMA DO MERCADO BRASILEIRO DE GÁS NATURAL E SUA PERSPECTIVA PARA A EXPLORAÇÃO DO SHALE GAS, 2016.

MONTEIRO, GUILHERME COUTINHO. ESTUDO DE GÁS DE FOLHELHO NA FORMAÇÃO PONTA GROSSA, BACIA DO PARANÁ.

NETO, Eduardo Ribeiro. Análise SWOT - Planejamento estratégico para análise de implantação e formação de equipe de manutenção em uma empresa de segmento industrial. Trabalho de conclusão de curso. Faculdade Pitágoras, São João Del Rei, MG, 2011.

SANBERG, Eduardo et al. Aspectos ambientais e legais do método fraturamento hidráulico no Brasil. 2015.

SCHEIBE, L.F. et al. Explotação do gás de xisto por fraturamento ameaça os aquíferos de água doce do Brasil. Mesa redonda: Gás de xisto: Desafios e perspectivas. In: 65 $5^{\text {a }}$ Reunião Anual da SBPC, 2013, Recife. Anais. Pernambuco. 2013.

SCHEIBE, Luiz Fernando; HENNING, Luciano Augusto; NANNI, Arthur Schmidt. ASPECTOS TERRITORIAIS DA EXPLORAÇÃO DO GÁS DE FOLHELHO (GÁS DE XISTO) POR FRATURAMENTO HIDRÁULICO. Águas

Subterrâneas, 2015. 